\title{
Malaria Parasite Liver Infection and Exoerythrocytic Biology
}

\author{
Ashley M. Vaughan ${ }^{1}$ and Stefan H.I. Kappe ${ }^{1,2}$ \\ ${ }^{1}$ Center for Infectious Disease Research, formerly Seattle Biomedical Research Institute, Seattle, \\ Washington 98109 \\ ${ }^{2}$ Department of Global Health, University of Washington, Seattle, Washington 98195 \\ Correspondence: stefan.kappe@cidresearch.org
}

In their infection cycle, malaria parasites undergo replication and population expansions within the vertebrate host and the mosquito vector. Host infection initiates with sporozoite invasion of hepatocytes, followed by a dramatic parasite amplification event during liver stage parasite growth and replication within hepatocytes. Each liver stage forms up to 90,000 exoerythrocytic merozoites, which are in turn capable of initiating a blood stage infection. Liver stages not only exploit host hepatocyte resources for nutritional needs but also endeavor to prevent hepatocyte cell death and detection by the host's immune system. Research over the past decade has identified numerous parasite factors that play a critical role during liver infection and has started to delineate a complex web of parasite-host interactions that sustain successful parasite colonization of the mammalian host. Targeting the parasites' obligatory infection of the liver as a gateway to the blood, with drugs and vaccines, constitutes the most effective strategy for malaria eradication, as it would prevent clinical disease and onward transmission of the parasite.

$T_{\mathrm{f}}^{\mathrm{h}}$ he genus Plasmodium consists of many different parasite species, each with a narrow host range and the causative agent of the disease malaria in its respective host. Plasmodium parasites have evolved exceedingly complex life cycles, using mosquitoes as the vehicle of transmission to infect reptiles, birds, and mammals, including humans. Human malaria parasite infection inflicts tremendous morbidity and significant mortality, mainly caused by two parasite species, Plasmodium falciparum and Plasmodium vivax. When the parasites' sporozoite stages are transmitted by a mosquito bite, these preerythrocytic forms establish the gateway to host infection by invading host cells and initiating the first round of intracellular replication. Preerythrocytic infection precedes blood stage infection and, for all Plasmodium species that infect mammals, takes place in hepatocytes within the liver. Hence, the intrahepatocytic replication stages are called liver stages or exoerythrocytic forms (EEFs). Liver infection is completely asymptomatic; thus, it cannot be detected in humans and, in consequence, cannot be directly studied during natural infection. Fritz Schaudinn's infamous blunder at the turn of the 19th century, the alleged observation that sporozoites could directly infect red blood cells,

Editors: Dyann F. Wirth and Pedro L. Alonso

Additional Perspectives on Malaria: Biology in the Era of Eradication available at www.perspectivesinmedicine.org

Copyright (C) 2017 Cold Spring Harbor Laboratory Press; all rights reserved; doi: 10.1101/cshperspect.a025486

Cite this article as Cold Spring Harb Perspect Med 2017;7:a025486 
A.M. Vaughan and S.H.I. Kappe

held back research on preerythrocytic infection for decades, and it was only in the late 1940s that the liver stages of the parasite were discovered. This breakthrough was made possible by the discovery of rodent malaria parasites such as Plasmodium yoelii and Plasmodium berghei, and their introduction into laboratory research, which provided exceptionally powerful experimental tools for the direct analysis of liver infection. Indeed, most of the data concerning preerythrocytic infection have been generated with these models. Preerythrocytic stages of human malaria parasites remain exceedingly difficult to study. However, the development of in vitro platforms for the culture of human hepatocytes and the development of liver-humanized mice provide, for the first time, powerful preerythrocytic infection models, which are revolutionizing research on the initial stages of human malaria parasite infection. Here, we review the biology of liver infection by sporozoites and liver stage development, raise outstanding questions regarding the field, highlight opportunities for future research, and argue for the liver stages as the essential target for malaria eradication efforts.

\section{HEPATOCYTE INVASION AND TRANSITION TO LIVER STAGE}

After an infectious mosquito bite, sporozoites must leave the bite site and find their way to hepatocytes, where liver stage development occurs. The dermis-to-hepatocyte journey (reviewed in Ejigiri and Sinnis 2009) is complex and perilous for the sporozoites and their numbers are modest, yet a single infectious mosquito bite leads to liver infection, thereby setting the stage for successful host colonization. The sporozoite (Fig. 1A) is a unique invasive stageunlike the parasite's ookinete stage that only traverses across the basal lamina of the mosquito midgut (Vinetz 2005) and the merozoites that only invade red blood cells (Cowman et al. 2012)—sporozoites are highly motile and must traverse and invade cells. They enter the bloodstream by traversing a dermal capillary, are transported to the hepatic capillary network (the sinusoids), and then traverse across the endothelial barrier to enter the hepatic parenchyma. Here, sporozoites traverse multiple hepatocytes and then finally undergo a functional switch that allows them to invade a hepatocyte to take up residence. During and after invasion, the sporozoite releases the contents of a unique set of invasive organelles, the micronemes and rhoptries, whose constituent proteins mediate molecular interactions with the host cell (Fig. 1A-C). The molecular mechanisms and sequence of events in cell invasion have been extremely well dissected with regard to merozoite invasion of red blood cells, but much less is known about hepatocyte infection by sporozoites. Merozoite and sporozoite host cell invasion share commonalities, such as the parasite actin-myosin motor that powers active entry into the host cell (Fowler et al. 2004) and the host cell plasma membrane invagination during invasion that ensconces the intracellular parasite within a host membrane, known as the parasitophorous vacuole membrane (PVM) (Fig. 1D) (Meis et al. 1983). The PVM is extensively modified by the developing liver stage parasite and acts not only as a barrier to the host cell cytoplasm but also as a conduit for communication and nutrient acquisition (Figs. 1E and 2A,B). Research has revealed some of the key molecular players, both parasite and host, in the hepatocyte invasion process, many of which are unique to sporozoites.

The major sporozoite surface protein, circumsporozoite protein (CSP), is a key mediator of the sporozoites' interaction with the host during its journey to the liver and the infection of hepatocytes. CSP is composed of a central repeat region, diverse across Plasmodium species, flanked by two conserved domains - the amino-terminal region I and a cell-adhesive carboxy-terminal motif known as the type I thrombospondin repeat (TSR). Region I masks the adhesive TSR until the sporozoite reaches the liver at which time it is cleaved, allowing the TSR to mediate hepatocyte adhesion (Coppi et al. 2011). This begs the question, how does the sporozoite know it has reached the liver? Localized within the liver sinusoid are highly sulfated heparin sulfate proteoglycans (HSPGs), produced by stellate cells within the space of 
A

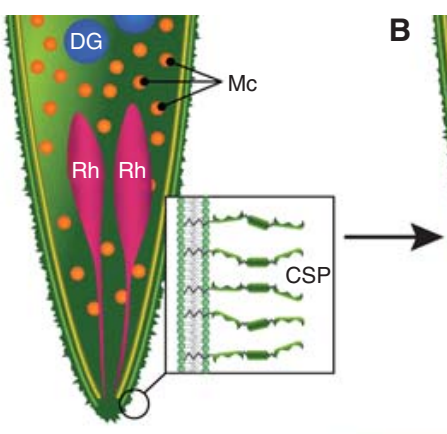

B

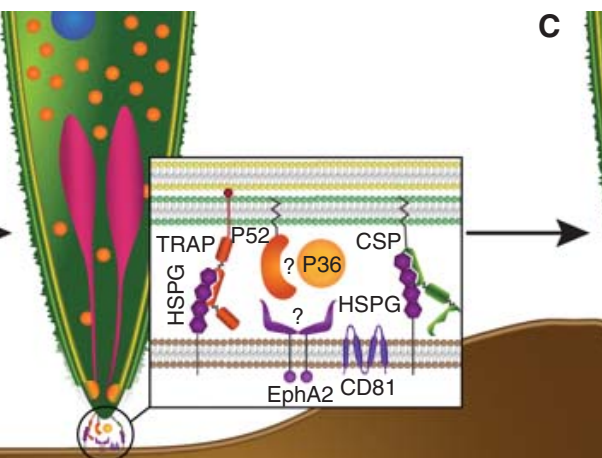

C

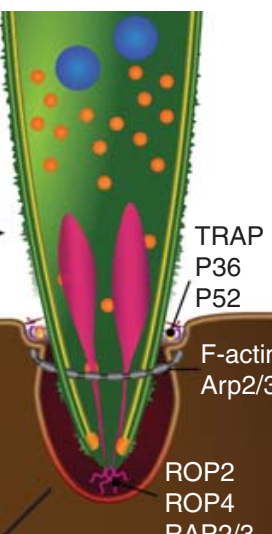

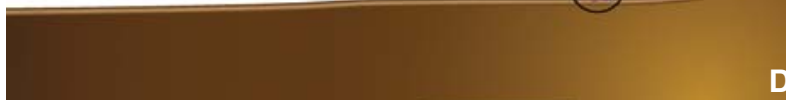

D $\mathrm{RAP} 2 / 3$

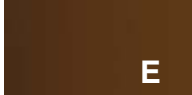

E
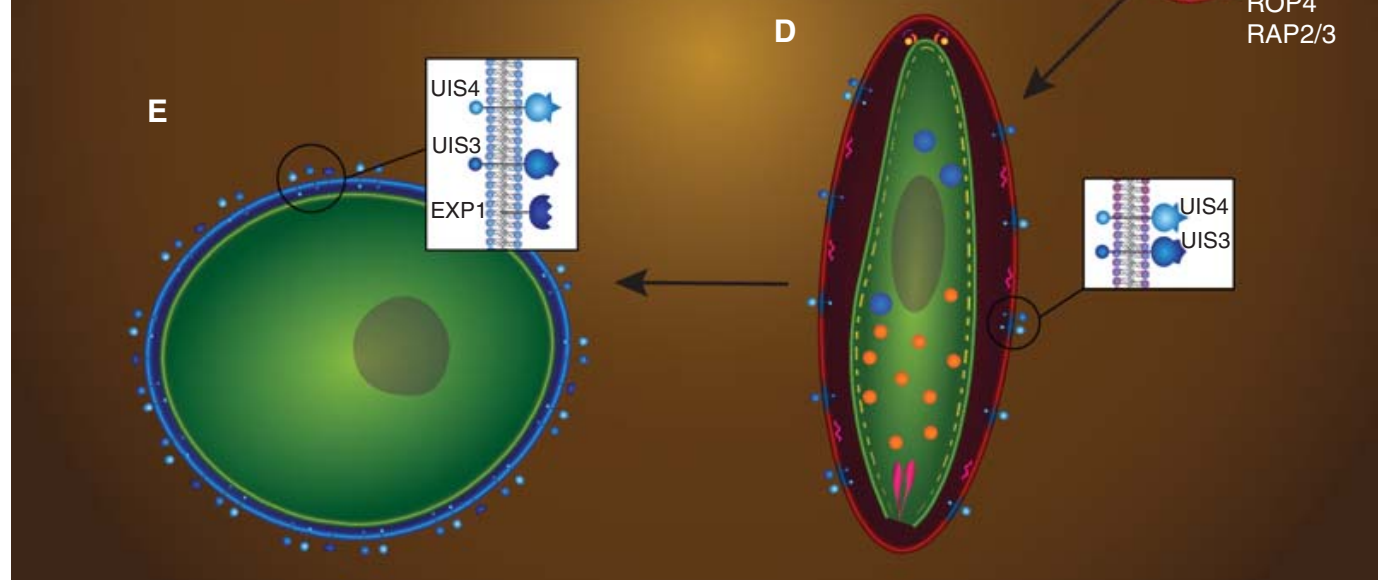

Figure 1. Sporozoite invasion of host hepatocytes. Graphic representation of the invasion steps that culminate in the productive infection of the hepatocyte host cell. (A) The surface of the motile sporozoite is coated with circumsporozoite protein (CSP) (shown in inset), which engages heparin sulfate proteoglycans (HSPGs) on the hepatocyte surface. The apical end of the sporozoite contains organelles whose contents are essential for hepatocyte invasion: rhoptries (Rh, pink), micronemes (Mc, orange), and likely dense granules (DG, blue), although the latter have not been unequivocally identified. $(B, C)$ Contact with an invasion-permissive hepatocyte (brown) triggers CSP processing, which, via an unknown mechanism, triggers the release of invasionessential proteins from the micronemes (inset). These proteins include thrombospondin-related adhesive protein (TRAP), which binds to HSPGs on the hepatocyte cell surface and to the sporozoite internal glideosome complex (not shown) via its cytoplasmic domain to provide traction for the invading sporozoite at the moving junction (also known as the tight junction, shown as a gray ring). The microneme proteins P52 and P36 are also involved in the invasion process and may interact with each other as well as interacting with the hepatocyte Ephrin A2 receptor (EphA2). The P52/P36/EphA2 axis appears to be critical for the formation of the parasitophorous vacuole (PV). The hepatocyte receptor CD81 is also important for the invasion process and PV formation, but it is not clear whether the sporozoite directly interacts with it. The inner membrane complex (IMC) (in yellow) anchors the internal glideosome complex, allowing for sporozoite movement into the hepatocyte. Hepatocyte invasion occurs through the moving junction at the point of entry and is accompanied by the polymerization of host F-actin in association with Arp2/3. Invasion results in the invagination of the hepatocyte plasma membrane and the release of rhoptry proteins, including ROP2, ROP4, and RAP2/3. (D) Successful invasion results in the sporozoite residing within a PV surrounded by a parasitophorous vacuole membrane (PVM) of hepatocyte origin. The PVM is extensively modified by the parasite and the putative dense granule proteins UIS3 and UIS4 are released and trafficked to the PVM, as is EXP-1 (inset). During sporozoite dedifferentiation, the IMC (dashed yellow line) and the apical organelles are broken down. (E) The nascent liver stage trophozoite resides within a PV, has its own parasite plasma membrane still coated by CSP (green), and is surrounded by a PVM (blue). 
A

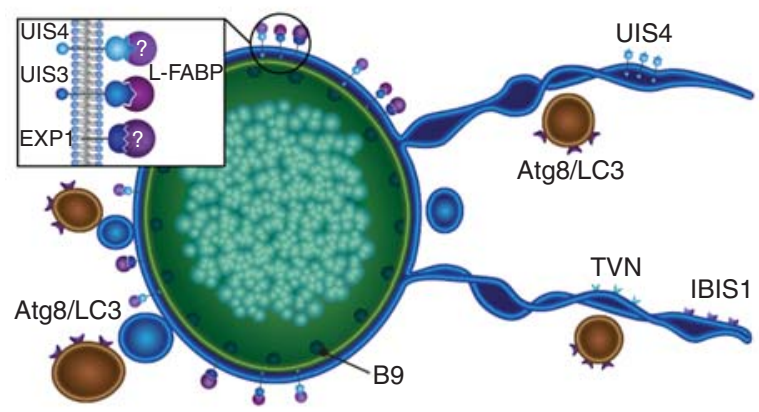

B

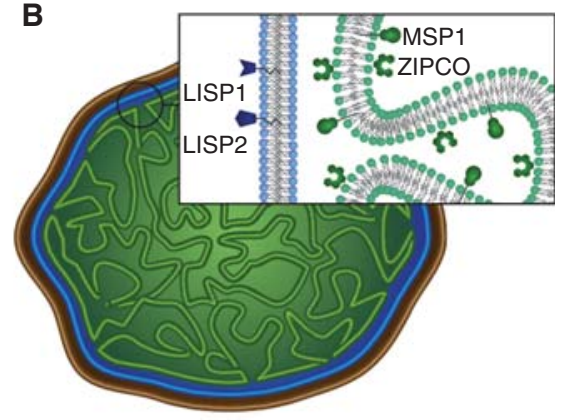

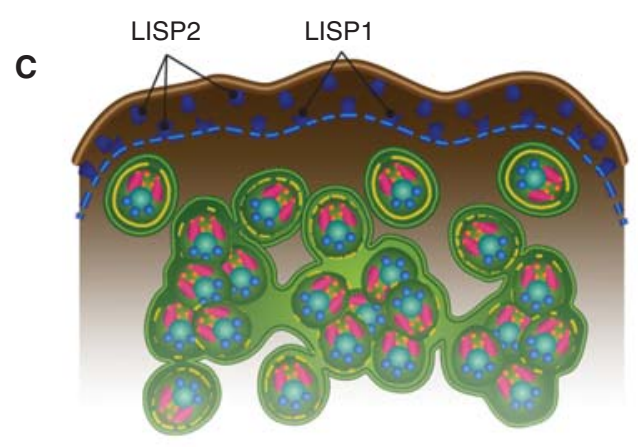

D

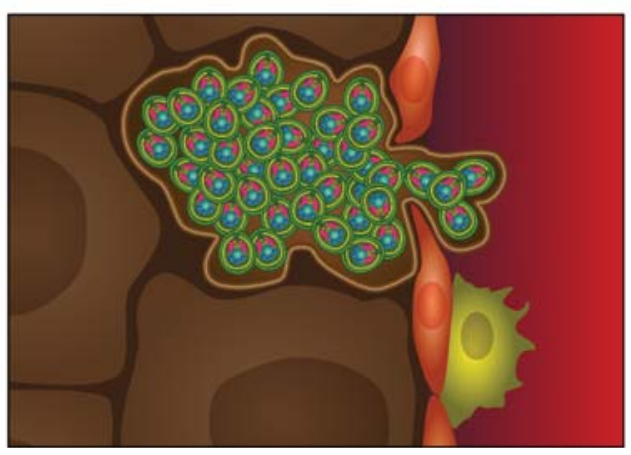

Figure 2. Liver stage development. Graphic representation of liver stage maturation that leads to the formation of exoerythrocytic merozoites. (A) The tubulovesicular network (TVN) (blue)-membrane-bound extensions and whorls that emanate from the parasitophorous vacuole membrane (PVM) -interacts with the hepatocyte's autophagosomes (which express Atg8/LC3) likely for nutrient uptake. Parasite proteins expressed on the PVM/ TVN include IBIS1, EXP1, UIS4, and UIS3, which has been shown to interact with host L-FABP. The parasite plasma membrane (PPM)-associated protein B9 is known to be important for liver stage development. (B) As the liver stage parasite matures, multiple invaginations of the PPM occur (cytomere formation), and this is accompanied by the expression of MSP1 and ZIPCO. Additionally, LISP1 and LISP2 expression occur on the PVM. (C) Toward the end of liver stage development, individual exoerythrocytic merozoites begin to form, the PVM breaks down (a process that relies on LISP1), and LISP2 is released into the host hepatocyte. $(D)$ Merosomes, merozoites surrounded by hepatocyte plasma membrane, are released into the bloodstream through the liver sinusoid, which is demarcated by epithelial cells (red) and liver resident macrophages, the Kupffer cells (yellow).

Disse, and these HSPGs are recognized by the sporozoite via CSP (Fig. 1B) (Frevert et al. 1993). This might lead to a signaling event that switches the sporozoite to an invasive phenotype (Coppi et al. 2007), resulting in the aforementioned cleavage of region I, a process that is catalyzed by a sporozoite protease (Coppi et al. 2005).

CSP cleavage appears to be a prerequisite for productive infection, but what other molecules are involved in the process? A number of sporozoite micronemal proteins are known to be crucial and they include thrombospondin- related anonymous protein (TRAP) and the 6-cys domain proteins P52 and P36 (Fig. 1B). TRAP is a type 1 transmembrane protein, and like CSP, it contains a TSR domain but also an integrin-like domain. TRAP is released onto the sporozoite surface from the micronemes during invasion and, during this process, TRAP binds to the sporozoite actin-myosin motor through its carboxy-terminal cytoplasmic domain and binds to HSPGs through its extracellular domain (Kappe et al. 1999). During invasion, TRAP is translocated from the anterior to the posterior of the sporozoite and is subsequently 
shed from the sporozoite by cleavage within its transmembrane domain, likely by the rhomboid protease ROM4, which allows for hepatocyte invasion, because the cleavage releases the TRAP-HSPG bond (Baker et al. 2006; Ejigiri et al. 2012) (Fig. 1B). The micronemal proteins P52, a predicted GPI-anchored protein, and P36, a predicted secreted protein, are members of the 6-cys protein family (Templeton and Kaslow 1999), and they are critical for hepatocyte infection (Fig. 1B,C). Other members of the 6-cys family that are expressed in different parasite stages also have roles in parasite-parasite or host-parasite interactions (Pradel 2007; van Dijk et al. 2010; Molina-Cruz et al. 2013; Sala et al. 2015). The 6-cys domains are likely involved in protein-protein interaction, but evidence for this has been scarce. P52 is released from the micronemes to the sporozoite surface before invasion and disruption of either P52 or P36 in P. berghei (Ishino et al. 2005; van Schaijk et al. 2008), and P52 in P. falciparum (van Schaijk et al. 2008) results in sporozoites that are defective in hepatocyte invasion. In P. yoelii, the simultaneous deletion of $P 36$ and P52 renders sporozoites unable to form or maintain a PVM, resulting in early abortion of liver stage development (Labaied et al. 2007). Similarly, $P$. falciparum sporozoites lacking P36 and P52 cannot develop after hepatocyte entry (VanBuskirk et al. 2009). Recent work revealed the hepatocyte receptor that directly interacts with these proteins: the transmembrane receptor Ephrin A2 (EphA2) (Fig. 1B). EphA2 is essential for sporozoite invasion and concomitant PVM formation in rodent and human malaria parasites and antibodies to EphA2 block sporozoite infection (Kaushansky et al. 2015). Intriguingly, its natural ligand EphrinAl shares structural similarity with the 6-cys fold and there is strong evidence that EphA2 directly interacts with P36, thus constituting the first bona fide host receptor-parasite ligand pair with a critical role in hepatocyte infection (Fig. 1B).

In addition to EphA2, other hepatocyte surface proteins are critical for successful sporozoite infection. The tetraspanin membrane protein "cluster of differentiation 81" (CD81) (Fig. 1B) is required on hepatocytes for P. yoelii and $P$. falciparum sporozoite invasion with PVM formation but interestingly not for P. berghei. P. yoelii sporozoites are unable to infect CD81-deficient mouse hepatocytes, and antibodies against mouse and human CD81 inhibit the in vitro hepatocyte infection by $P$. yoelii and $P$. falciparum sporozoites (Silvie et al. 2003). Yet, a sporozoite ligand for CD81 has not been identified. Cholesterol is involved in the assembly of CD81-rich microdomains on the cell surface, and this assembly is necessary for sporozoite infection (Silvie et al. 2006), indicating that it is the organization and composition of microdomains, rather than a direct interaction with CD81, that enable successful sporozoite infection of hepatocytes. A further hepatocyte membrane receptor, scavenger receptor BI (SR-BI), which mediates the selective uptake of cholesteryl esters from both high- and low-density lipoproteins, plays a role in hepatocyte infection. This role appears rather indirect because SR-BI deficiency causes a decreased expression of CD81 on the hepatocyte surface (Yalaoui et al. 2008). Antibodies to SR-BI do not block sporozoite invasion (Foquet et al. 2015), adding credence to the idea that SR-BI expression is necessary for CD81 microdomain formation but not a receptor for the sporozoite. Recently, an important link between the initial interaction of the sporozoite with the hepatocyte surface and the signaling to trigger processes within sporozoites has been revealed-the presence of CD81 on hepatocytes appears to be critical for the subsequent discharge of the rhoptries (Risco-Castillo et al. 2014). Research thus indicates an orchestrated sequence of events whereby sporozoite interaction with the hepatocyte promotes downstream signaling that triggers the secretion of proteins necessary for the formation and modification of the PVM.

Once the sporozoite lies completely ensconced in the PVM (Fig. 1D), it must metamorphose into a highly metabolically active intracellular replication machine, a process that requires jettisoning or disassembling its invasive organelles and inner membrane complex (IMC) (Fig. 1D). IMC breakdown is accompanied by spherical plasma membrane expansion in the center of the still elongated parasite and 
A.M. Vaughan and S.H.I. Kappe

the contraction of its distal ends (Jayabalasingham et al. 2010). This shape conversion is accompanied by the clearance of the IMC and invasion-associated organelles, which are discharged as large exocytic vesicles or possibly undergo autophagy. However, the presence of autophagy in Plasmodium is controversial because the key autophagy marker protein Atg8/ LC3 localizes to the parasite apicoplast and does not relocalize to autophagosome-like vesicles or vacuoles (Eickel et al. 2013; Jayabalasingham et al. 2014). The nascent liver stage preferentially develops in the host juxtanuclear region and the PVM appears to form an association with the host endoplasmic reticulum (ER) (Bano et al. 2007). Parasite modification of the PVM allows the passage of molecules of up to $855 \mathrm{Da}$ from the host cytosol to the PV through open channels, and it is possible that host-derived cholesterol that accumulates at the PVM may modulate channel activity (Bano et al. 2007). These channels ensure that molecules from the nutrient-rich hepatocyte can feed the growing liver stage, although a tubulovesicular network, described below, likely allows for the uptake of larger molecules. Although the PVM is vital for successful liver stage development, the initial metamorphosis from sporozoite to trophozoite can occur outside a host cell. This indicates that the intracellular environment does not provide specific signals to trigger this process but rather that more general changes that occur with the sporozoites transition into a mammalian host, such as an elevation in temperature and the presence of serum components (Kaiser et al. 2003).

As described above, the initiation of liver stage development is a complex process that is initiated when the sporozoite detects a suitable hepatocyte for infection. Once the sporozoite has invaded its host cell, it must then dedifferentiate from an invasive extracellular parasite into an intracellular trophozoite contained within a PVM. During this process, signaling events prevent the parasites' destruction by the host cell. Finally, the trophozoite transitions into a highly replicative schizont that relies on nutrient uptake from its host as well as its own metabolic processes to ensure its eventual goal of exoerythrocytic merozoite release.

It must be noted that the transition to schizogony, which always occurs in P. falciparum liver stage development, does not always occur in $P$. vivax. The $P$. vivax sporozoite, once it has entered a host hepatocyte, dedifferentiates and can then become a dormant trophozoite, known as the hypnozoite. The hypnozoite can lie dormant for months and even years and then reactivate and fully develop, leading to $P$. vivax malaria relapses. The processes that lead to hypnozoite formation and reactivation are very poorly understood, and malaria elimination must address the radical cure of the dormant hypnozoite.

\section{LIVER STAGE DEVELOPMENT}

The liver stage undergoes schizogony-nuclear division without cell division-during its maturation and only in the final phase of this process do invasive exoerythrocytic merozoites form. Liver stage schizogony constitutes one of the most rapid eukaryotic replication eventsin a little $>2 \mathrm{~d}$, rodent malaria sporozoites can transform into a mature ellipsoid liver stage containing up to 29,000 exoerythrocytic merozoites (Baer et al. 2007). Liver stage development in $P$. falciparum takes longer, $\sim 6.5 \mathrm{~d}$, with estimates of up to 90,000 exoerythrocytic merozoites packaged in the fully mature parasite (Vaughan et al. 2012). Liver stage schizogony is characterized by the rapid branching and growth of the parasite's organelles such as the mitochondria and the relict plastid organelle, the apicoplast (Stanway et al. 2009), as well as massive DNA replication. Studies utilizing parasite and host transgenesis have shed light on the important pathways that allow for parasite growth, and, not surprisingly, a number of parasite proteins involved in PVM formation and modification are essential for liver stage formation and development.

The liver stage PVM proteins UIS3 and UIS4 are encoded by genes belonging to the up-regulated in infective sporozoites (UIS) group (Figs. 1D-E, 2A, 3A-C,F). These genes are highly transcribed in sporozoites when they 
A

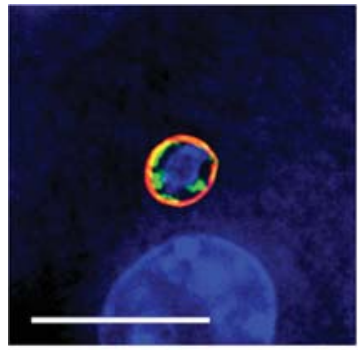

B

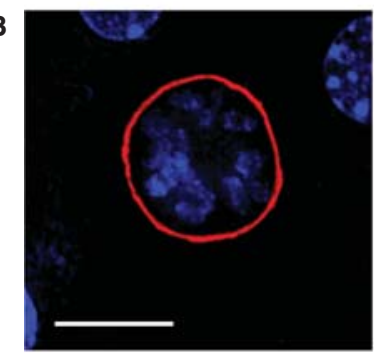

D
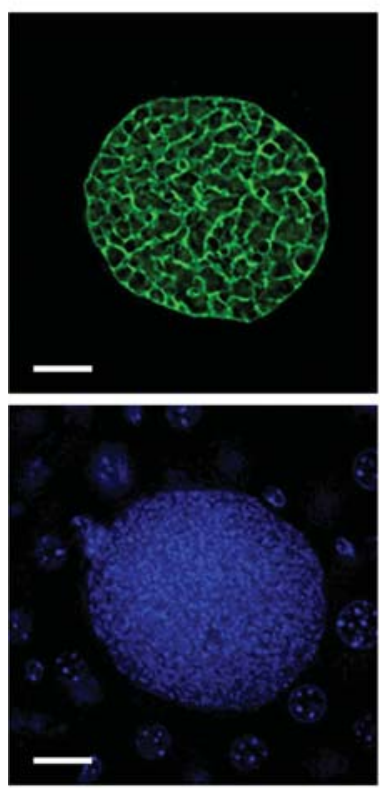
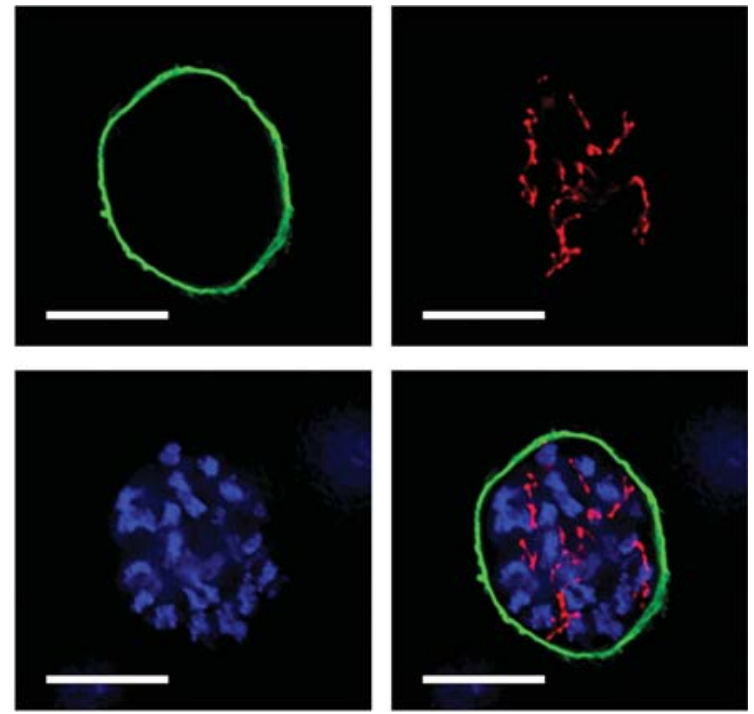

E
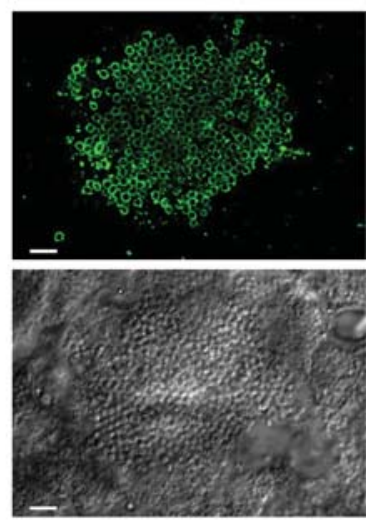

$\mathbf{F}$

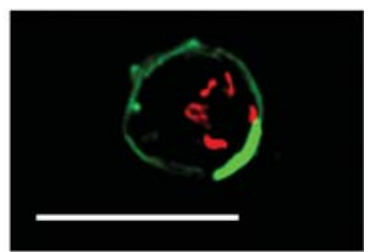

Figure 3. Immunofluorescence images of liver stage development. (A-E) Plasmodium yoelii liver stage development in a mouse liver. $(A)$ The spherical, early liver stage parasite, $12 \mathrm{~h}$ after sporozoite invasion, is significantly smaller than the host hepatocyte nucleus (blue). The liver stage parasitophorous vacuole (PVM) is shown in red (UIS4 expression), the endoplasmic reticulum (ER) is shown in green (BiP expression), and the parasite contains a single nuclear center (blue). (B) By $24 \mathrm{~h}$, the P. yoelii liver stage parasite (the UIS4-positive PVM is shown in red) has entered schizogony (multiple centers of nuclear replication [blue]). (C) At $30 \mathrm{~h}$ of development, the $P$. yoelii liver stage (the UIS4 PVM is shown in green) has undergone multiple rounds of nuclear replication (blue) and contains a highly branched apicoplast (acyl carrier protein expression, shown in red). (D) Late in P. yoelii liver stage development $(48 \mathrm{~h})$, the parasite plasma membrane (PPM) undergoes extensive invagination resulting in cytomere formation (MSP1, green). LISP2 (red) is expressed on the PVM as well as the hepatocyte membrane (white arrows). The nuclei (blue) of the individual parasites can be seen within the liver stage parasite. (E) At the end of liver stage development $(52 \mathrm{~h})$, individual exoerythrocytic merozoites (MSP1 expression in green, upper panel, delineates the merozoite membrane) can be seen within the mature liver stage parasite (differential interference contrast, lower panel). $(F)$ Image of a $P$. vivax hypnozoite in a humanized mouse liver. The hypnozoite remains latent, is small, and does not replicate its DNA, and its PVM has a unique UIS4-positive prominence (green). The hypnozoite mitochondrion (HSP60 expression) is shown in red and is branched. Scale bars, $10 \mu \mathrm{m}$. 
A.M. Vaughan and S.H.I. Kappe

still reside in the mosquito salivary glands but some are translationally repressed with protein production peaking only after hepatocyte invasion. This "just in time" protein expression from stored mRNAs exemplifies one of the approaches the sporozoite has evolved to ready itself for the rapid transition to liver stage replication and indicates that proteins such as UIS3 and UIS4 must be playing an important role starting very early in liver stage development. Indeed, deletion of either UIS3 or UIS4 gene causes arrest of early liver stage development (Mueller et al. 2005a,b; Jobe et al. 2007). The carboxyl termini of both UIS3 and UIS4 face the hepatocyte cytoplasm and the amino termini the PV lumen, suggestive of roles in parasitehepatocyte interactions. Indeed, UIS3 interacts with liver fatty acid protein (L-FABP) (Fig. 2A) (Mikolajczak et al. 2007), suggesting an interaction that could serve as a conduit for the transport of lipid into the liver stage to support growth. Lipid transport within and between eukaryotic cells can occur through membranebound ATP-binding cassette (ABC) transporters, and the ABCC class of transporters is expressed by both $P$. berghei and $P$. falciparum liver stages. Interestingly, the deletion of $A B C C 2$ (also known as MRP2) in both $P$. berghei and $P$. falciparum leads to liver stage arrest, demonstrating the importance of parasite ABC transporters in liver stage development and hinting to their role in lipid transport (Rijpma et al. 2016). To date, UIS4 function has remained elusive, as has the function of a second PVMresident protein exported protein 1 (EXP1, also known as Hep17 in rodent malaria parasites) (Fig. 2A). Later in liver stage development, two further PVM-associated proteins are expressed, LISP1 and LISP2 (Figs. 2B,C and 3D) (Ishino et al. 2009; Orito et al. 2013). LISP1 is involved in PVM breakdown and subsequent merozoite release, whereas LISP2 (which contains a modified 6-cys domain) is localized to the PV and PVM and is also transported to the cytoplasm and plasma membrane of infected hepatocytes (Figs. 2B,C and 3D). Although the functions of these two proteins are not fully understood, gene deletion studies in $P$. berghei have indicated their importance in late liver stage growth because parasites that lack LISP1 or LISP2 do not mature effectively. Further critical proteins expressed by liver stage parasites include the 6-cys-like protein, B9, expressed on the parasite plasma membrane (PPM) (Fig. 2A) (Annoura et al. 2014) and ZIPCO, an iron transporter expressed on the late liver stage PPM (Fig. 2B) (Sahu et al. 2014). Although an increasing number of PV and PVM proteins have been identified that play important roles in liver stage development, an important future goal is the comprehensive identification of all liver stage PVM, PV, and PPM proteins that will supersede the current identification of important players using candidate approaches. Importantly, research needs to go beyond the assembly of "parts lists" and ought to delineate the relationship and interaction among liver stage PVM and PV proteins and their interaction with host proteins to establish a network of important liver stage-hepatocyte interactions.

Although the liver stage clearly parasitizes the extremely metabolically active host hepatocyte, the massive increase in parasite biomass during liver stage development likely requires the participation of parasite anabolic pathways. Indeed, combined transcriptome and proteome analysis of liver stage development showed that the parasite de novo type II fatty acid synthesis pathway (FAS II) is highly active (Tarun et al. 2008). To assess the importance of FAS II, which is localized to the parasite apicoplast, gene knockouts in rodent malarias have been performed and showed that FAS II is critical for late liver stage development (Yu et al. 2008; Vaughan et al. 2009; Pei et al. 2010; Falkard et al. 2013; Lindner et al. 2014). These reports show that the liver stage requires its own fatty acid synthesis, but it is not currently understood why the fatty acids are synthesized-they might be incorporated into exoerythrocytic merozoite membranes, but they could also be incorporated into the growing hepatocyte plasma membrane or the PVM. As mentioned above, the UIS3/L-FABP interaction likely allows for lipid acquisition from the hepatocyte. The cholesterol component of this lipid can be derived from low-density lipoprotein internalization by the hepatocyte as well as de novo synthesized hepa- 
tocyte cholesterol (Labaied et al. 2011). Further research has shown that hepatocyte phosphatidylcholine, the major membrane phospholipid, is taken up by liver stages, and preventing the rate-limiting steps in the synthesis of hepatocyte phosphatidylcholine affects liver stage development (Itoe et al. 2014). All of these studies show that liver stage parasites critically depend on both lipid uptake from the host hepatocyte and endogenous lipid synthesis to support their dramatic growth and differentiation.

During growth, liver stage mass increases so much that the infected hepatocyte must significantly expand to accommodate the replicating parasite. However, the liver stage parasites remain relatively undifferentiated until shortly before completion of liver stage maturation. Late in development, the PPM undergoes rapid expansion and extensive invagination (called cytomere formation) (Figs. 2B and 3D), which dramatically increases parasite surface area and enables rapid formation of individual exoerythrocytic merozoites (Figs. 2C and $3 \mathrm{E}$ ). This process also requires coordinated nuclear and organellar fission to ensure partitioning of nuclei and organelles into nascent merozoites (Stanway et al. 2011). This coordinated fission likely relies on both DNA- and RNA-binding proteins, and a liver stage-specific RNA-binding protein, PlasMei2, appears to be essential for the partitioning of nuclear DNA. The deletion of PlasMei2 in P. yoelii, without affecting liver stage growth, prevents the partitioning of nuclear DNA, and this in turn prevents the formation of exoerythrocytic merozoites (Dankwa et al. 2016). Once merozoites have fully formed, the PVM must break down (Fig. 2C) before they can be released, and this process is a result of changes in PVM permeability (Sturm et al. 2009) and relies on a parasite phospholipase, which localizes to the PVM (Burda et al. 2015).

Intravital microscopic observations of livefluorescent $P$. yoelii and $P$. berghei mature liver stages in mice have shown that they induce the detachment of their host hepatocyte, leading to the budding of merosomes (merozoite-filled vesicles) into the sinusoidal lumen (Fig. 2D) (Sturm et al. 2006; Tarun et al. 2006). The mer- osome membrane derives from the host hepatocyte plasma membrane (Graewe et al. 2011), allowing the merosome to hide from the immune system and thereby avoid uptake and destruction by the numerous liver-resident macrophages (the Kupffer cells), on its way to the bloodstream. Merosomes have also been observed in mature $P$. falciparum liver stages (Vaughan et al. 2012), confirming their existence in human malaria parasite liver stages. Most $P$. yoelii merosomes exit the liver intact and adapt to a relatively uniform size, within which 100 to 200 merozoites reside (Baer et al. 2007). Merosomes eventually break up inside pulmonary capillaries, resulting in merozoite liberation and red blood cell infection.

\section{PARASITE PERTURBATIONS OF HOST HEPATOCYTES}

So far, we have discussed parasite proteins and some host molecules that are necessary for sporozoite invasion and liver stage development, but to acquire nutrients and grow, the parasite must not simply reside in the hepatocyte and exploit it but actively manipulate and subvert it to avoid its demise. How does this happen? Already at the point of invasion, the parasite subverts its host. As the sporozoite invades, it induces the formation of a ring-shaped structure in the hepatocyte composed of de novo polymerized host F-actin (Fig. 1C) (Gonzalez et al. 2009). The hepatocyte Arp2/3 complex, an actin-nucleating factor, is recruited to this ring structure and is necessary for parasite invasion (Fig. 1C). The PVM is essential for liver stage development, and the formation of a productive PVM is a prerequisite for the parasite's ability to render its host hepatocyte resistant to apoptosis (van de Sand et al. 2005; van Dijk et al. 2005; Kaushansky et al. 2013a). Although the sensitivity to apoptosis is dependent on the Bcl-2 family of mitochondrial proteins that the parasite subverts (Kaushansky et al. 2013a), the parasite molecules that interfere with hepatocyte apoptosis are not known. A line of defense used by many host cells against pathogen infection is the synthesis of stress granules, thereby shutting down protein synthe- 
sis. However, there is no evidence that hepatocyte infection causes stress granule formation, which implies that the parasite has evolved to prevent this response from occurring in the hepatocyte (Hanson and Mair 2014). In a surprising twist on parasite-host manipulation, liver stage survival actually benefits from the host ER stress response pathway (Inacio et al. 2015), which typically shuts down cellular activity. Proteins and transcripts that act in the unfolded protein response leading to ER stress were found to be elevated in hepatocytes in response to infection, but why the parasite perturbs its host in this way is not clear. It is possible that ER stress supports parasite growth by regulating lipid metabolism, vital for parasite growth (Itoe et al. 2014), or diminishing antigen presentation so the liver stage can remain hidden from the immune system - a trick used by hepatitis C (Tardif and Siddiqui 2003).

The perturbations of the host hepatocyte have been explored by analyzing changes in hepatocyte transcription and protein expression early during liver stage infection (Albuquerque et al. 2009; Kaushansky et al. 2013b). Transcriptome data showed that parasite infection initially causes a global stress response, which then morphs into an engagement of host metabolic processes and the maintenance of cell viability to ensure parasite and host cell survival (Albuquerque et al. 2009). Using cell lysate arrays to simultaneously monitor many protein perturbations, a subset of hepatocyte protein levels and accompanying posttranslational modifications were measured $24 \mathrm{~h}$ postinfection with rodent malaria parasites and compared with uninfected hepatocytes (Kaushansky et al. 2013b). This revealed a signaling network aimed at preventing host cell death but also determined that the tumor suppressor P53 is substantially dampened in infected hepatocytes. This is of functional significance because increasing P53 levels whether chemically or genetically nearly eliminates liver stage infection and development and mice lacking P53 are hypersusceptible to infection (Kaushansky et al. 2013b).

During liver stage development, a tubulovesicular network (TVN) forms, which includes membranous extensions of the PVM as well as the creation of autonomous vesicular structures within the infected hepatocyte (Fig. 2A) (Mueller et al. 2005a). The TVN likely functions in hepatocyte interactions and in accessing nutrients from the hepatocyte, but these functions need to be experimentally verified. Fluorescent tagging of two P. berghei PVM proteins, UIS4 and IBIS1, and the use of correlative light-electron microscopy have shown that the TVN membranes extend throughout the host cell and include dynamic vesicles as well as long tubules that extend and contract from the PVM (Fig. 2A) (Grutzke et al. 2014). Additionally, labeling of host hepatocyte compartments revealed an association of late endosomes and lysosomes with the TVN-associated elongated membrane clusters. Furthermore, the host autophagosome protein Atg8/LC3 colocalizes with UIS4 at the PVM and TVN (Fig. 2A). These data suggest that the intimate association between the TVN and host endosomes/lysosomes allows for parasite-hepatocyte signaling as well as nutrient uptake. Further studies have shown that complete parasite development actually correlates with the gradual loss of autophagy marker proteins and associated lysosomes from the PVM even though other autophagic events such as nonselective canonical autophagy continue in the host cell (Prado et al. 2015). Thus, it is possible that the parasite continues to benefit from nonselective canonical autophagy for its growth.

Supporting the hypothesis that the endosomal system supports liver stage growth, the growth of the parasite is dependent on phosphoinositide 5-kinase (PIKfyve), which converts phosphatidylinositol 3-phosphate into phosphatidylinositol 3,5-bisphosphate (PI $(3,5)$ P2) within the endosomal system - an enzymatic reaction essential for late endocytic membrane fusion (Thieleke-Matos et al. 2014). Indeed, the PI $(3,5)$ P2 effector protein TRPML1, involved in late endocytic membrane fusion, was shown to be present in vesicles in close contact with the PVM and PIKfyve inhibition delayed parasite growth. Additionally, contents of late endocytic vesicles have been found within the parasite cytoplasm (Lopes da Silva et al. 2012). We are only just beginning to un- 
derstand how the parasite manipulates its host, and many questions remain unanswered. Most notably, there is a complete lack of understanding of how the liver stage, during its own massive growth, also enables the growth of the PVM and expansion of the host hepatocyte to accommodate its heft-cells do not normally dramatically increase in size, but the mature liver stageinfected hepatocyte can expand to 200 times its normal volume.

The developing liver stage parasite, as well as interacting with its host hepatocyte to ensure its survival, must also evade the host's immune system to ensure merozoite maturation and release. As noted above, the autophagy marker Atg8/LC3 colocalizes with UIS4 at the PVM and TVN, and aids in liver stage growth. Conversely, autophagy has been identified as a downstream pathway that is activated in response to interferon $\gamma($ IFN- $\gamma)$ in the control of intracellular infections (Deretic et al. 2013). Indeed, IFN- $\gamma$, a master regulator of immune functions, has been known for many years to induce the elimination of liver stage parasites in vivo (Ferreira et al. 1986). Thus, the parasite needs to precisely coordinate autophagy for its benefit. Research on $P$. vivax liver stages has shown that IFN- $\gamma$-mediated restriction of liver stage $P$. vivax depends on autophagy-related proteins including Beclin-1, PI3K, and Atg5 and enhanced the recruitment of LC3 to the PVM. In this case, the LC3 decoration of the PVM led to a noncanonical autophagy pathway resembling that of LC3-associated phagocytosis, promoting the fusion of $P$. vivax compartments with lysosomes and subsequent killing of the pathogen (Boonhok et al. 2016). Thus, research has uncovered positive and negative aspects of autophagy on parasite survival, and it is clear that although the parasite can take advantage of host cell autophagy, it can also be killed by the pathway and thus must carefully control this intracellular process for its own gain.

IFN- $\gamma$ production in response to liver stage parasite detection is part of a programmed innate immune response to liver stage infection (Liehl and Mota 2012). This innate immune response to infection is pronounced and can actually lead to the effective killing of a second- ary liver stage infection (Miller et al. 2014). This response is in part initiated by liver-resident cells and driven by Plasmodium RNA, which acts as a pathogen-associated molecular pattern capable of activating the type I IFN response via the cytosolic pattern recognition receptor Mda5 (Liehl et al. 2014). Furthermore, the response is abrogated in mice deficient in IFN- $\gamma$, as well as the type I IFN- $\alpha / \beta$ receptor (IFNAR), demonstrating the important role of IFNAR in driving the innate immune response (Liehl et al. 2014; Miller et al. 2014). The cell type linked to the secretion of IFN- $\gamma$ was shown to be $\mathrm{CD}_{4} 9 \mathrm{~b}^{+} \mathrm{CD}^{+}$natural killer T (NKT) cells and an increase in CD1d-restricted NKT cells was critical in reducing liver stage burden of a secondary infection (Miller et al. 2014). In turn, the lack of IFNAR signaling abrogated the increase in NKT cell numbers in the liver, showing a link between type I IFN signaling, cell recruitment, and parasite elimination (Miller et al. 2014).

The above highlights the extent of our current knowledge on how the liver stage parasite influences both the host hepatocyte and the host innate immune system. Far more research is necessary and will help in the design and implementation of drugs to target the liver stage parasite and effective vaccines that engender appropriate immune responses to liver stage parasites. For these advances to take place, we need better models for liver stage development and liver stage isolation.

\section{ADVANCES IN MODEL DEVELOPMENT FOR HUMAN MALARIA PARASITE LIVER INFECTION}

A natural sporozoite infection typically results in the productive invasion of only a small number of hepatocytes. Because of this bottleneck, the liver stage parasite has been extremely difficult to study. However, such studies are essential to uncover pathways that are necessary for parasite survival and replication. These pathways can then be perturbed to prevent development and ultimately to thwart life cycle progression to blood stage disease. To this end, parasite transgenesis has enabled the creation of fluorescent parasites and this led to the sorting of murine 
hepatocytes infected with $P$. yoelii fluorescent liver stages, resulting in the first extensive liver stage transcriptomes and proteomes (Tarun et al. 2008; Albuquerque et al. 2009). However, extensive -omic analysis of human malaria liver stages has still not been completed and needs to be performed. Such analysis is important for the reason that numerous studies have shown significant biological differences between rodent and human malaria parasites. Nevertheless, platforms for the growth of human malaria parasite liver stages are not easily established, because of the limitation that $P$. falciparum and $P$. vivax preerythrocytic stages only infect human and some nonhuman primate hepatocytes and do not grow well in hepatoma cells. Additionally, the $P$. vivax sporozoite, unlike the model rodent malaria sporozoite, can develop into either a liver stage schizont or a liver stage hypnozoite (Krotoski et al. 1982)—a dormant liver stage form (Fig. 3F) that can activate and cause malaria relapse infections in affected individuals.

In vitro development of $P$. vivax liver stages in primary human hepatocytes was first documented in 1984 (Mazier et al. 1984) and for P. falciparum in 1985 (Mazier et al. 1985), and both parasites were later shown to mature in the human hepatocyte cell line HC-04 (Sattabongkot et al. 2006), albeit poorly. Rapid advances in cryopreservation methods for primary human hepatocytes make this cell type more easily available, and investigators no longer depend on cells fresh from liver surgery. Recently, an improved in vitro system using primary human hepatocytes in a microscale human liver platform was shown to support $P$. falciparum and $P$. vivax liver stages development including P. vivax hypnozoite formation (March et al. 2013). An additional promising platform uses induced pluripotent stem cell-derived hepatocyte-like cells and liver stage development of both $P$. falciparum and $P$. vivax appears to mirror that observed in primary human hepatocytes (Ng et al. 2015). Thus, this platform is an attractive alternative because it enables a potential unlimited production of hepatocytes.

Although in vitro models for infection have greatly improved over the past years, robust in vivo infection models for preerythrocytic stages of human malaria parasites are highly desirable. Fortunately, human-liver chimeric mouse models that were originally developed for drug metabolism studies and hepatitis research are promising as animal models for human malaria liver infection. These models are all built around some form of immunocompromised background plus genetically encoded liver injury that selectively ablates mouse hepatocytes, thereby creating niches in the liver that can then be repopulated with primary human hepatocytes. An initial study using the SCID Alb-uPA mouse transplanted with human hepatocytes showed that $P$. falciparum liver stages developed after intravenous sporozoite injection (Sacci et al. 2006).

A second liver-chimeric mouse model, the FRG huHep mouse (Azuma et al. 2007), can yield up to $95 \%$ human hepatocyte chimerism. After intravenous injection of $P$. falciparum sporozoites into FRG huHep mice, complete liver stage development occurred, resulting in the creation of schizonts packed with tens of thousands of exoerythrocytic merozoites that were able to transition in vivo to red blood cell infection, which was then continuously maintained in vitro (Vaughan et al. 2012). This enabled the creation of $P$. falciparum genetic crosses, which were previously possible only in splenectomized chimpanzees (Vaughan et al. 2015). The FRG huHep mouse has, in addition, been used to show the efficacy of antibodies against sporozoite proteins to reduce or prevent $P$. falciparum liver infection (Sack et al. 2014). This has also been achieved in SCID Alb-uPA mice (Behet et al. 2014; Foquet et al. 2014). Together, the work establishes liver-chimeric mice as an important preclinical tool to assess interventions against human malaria parasite pre-erythrocytic stages and further refinement could ascertain their use as a new stepping-stone toward clinical testing of interventions in controlled human malaria infection trials.

Intriguingly, the FRG huHep mouse was also recently used for infections with $P$. vivax (Mikolajczak et al. 2015). In this study, robust liver infection with $P$. vivax sporozoites was observed that culminated in complete liver stage 
development and exoerythrocytic merozoite release $9.5 \mathrm{~d}$ after infection and infectious merozoites could be captured by the injection of human reticulocytes. Alongside liver stage development, the establishment and persistence of hypnozoites was observed, enabling, for the first time, a detailed characterization of this unique latent EEF. Although DNA replication did indeed not occur in hypnozoites as previously thought, in contrast to previously held assumptions, latent hypnozoites were not "dormant" but metabolically active, showing limited organelle replication and modest growth over time. Hypnozoites also exhibited a unique thickening of the PVM, called a "prominence," that appears to distinguish them from replicating liver stages (Fig. 3F). The study also showed that the FRG huHep mouse will be useful to model hypnozoite activation, which leads to the production of second- and third-generation exoerythrocytic merozoites and relapsing blood stage infection, which is a distinguishing clinical feature of $P$. vivax infection. Thus, the FRG huHep model might prove useful to test the effectiveness of drugs that can eliminate hypnozoites and thus prevent relapsing infection with P. vivax.

\section{VACCINATION WITH ATTENUATED PREERYTHROCYTIC PARASITES}

Following earlier research on bird malaria (which do not have a liver stage), a study in 1967 showed that mice inoculated with irradiation-attenuated $P$. berghei sporozoites induced protection from a subsequent infection with wild-type sporozoites (Nussenzweig et al. 1967) and with this, the concept of an attenuated, whole sporozoite malaria vaccine was born. Similar studies in humans with irradiated P. falciparum sporozoites showed equal promise (Clyde et al. 1973; Rieckmann et al. 1974). Subsequent work showed that attenuated sporozoites have to be infectious and invade hepatocytes to unfold their protective potential likely by virtue of expressing new antigens before the cessation of liver stage development. Live sporozoite immunization elicits both protective humoral responses and cellular responses (Doll and
Harty 2014). In the 1970s, irradiation-attenuated sporozoites were not considered a practical vaccine because of the issues with irradiation, mass production, preservation, and delivery. However, increasing success in producing and storing P. falciparum sporozoites, irradiated sporozoites gained a resurgent interest in the 2000s and intravenous inoculation of humans with cryopreserved, irradiated $P$. falciparum sporozoites recently showed complete protection from infectious sporozoite challenge (Seder et al. 2013).

The discovery of genes that are essential for liver stage development, discussed earlier, gave rise to the idea that attenuation of the parasite could be accomplished through engineered gene deletion within the parasite's complex genome, thus rendering irradiation obsolete. In this effort, vaccine development meets parasite biology and synergizes effectively to create a biologically informed malaria vaccine strategy. Today, numerous genes essential for liver stage development have been identified, mostly in rodent malaria models (Table 1). Gene deletions arrest the parasite at distinct points during liver stage development, and studies have shown that late liver stage-arresting parasites afford superior immunity when compared with both an early arresting, genetically engineered parasite and irradiation-attenuated sporozoites. This is due to the significant increase in antigen load and breadth, which engenders a broader and diversified immune response (Butler et al. 2011; Sack et al. 2015). Engineering of P. falciparum liver stage-attenuated parasites has been undertaken (VanBuskirk et al. 2009); the parasites have undergone initial human clinical trial testing and are now undergoing improvements in attenuation (Table 1) (Mikolajczak et al. 2014; van Schaijk et al. 2014b). Ultimately, this will likely yield an engineered parasite that can replace irradiated sporozoites and such a vaccine will play a crucial role in malaria elimination.

\section{FUTURE PERSPECTIVES}

A call for malaria eradication by 2040 is perceived to be an achievable goal (endmalaria 
A.M. Vaughan and S.H.I. Kappe
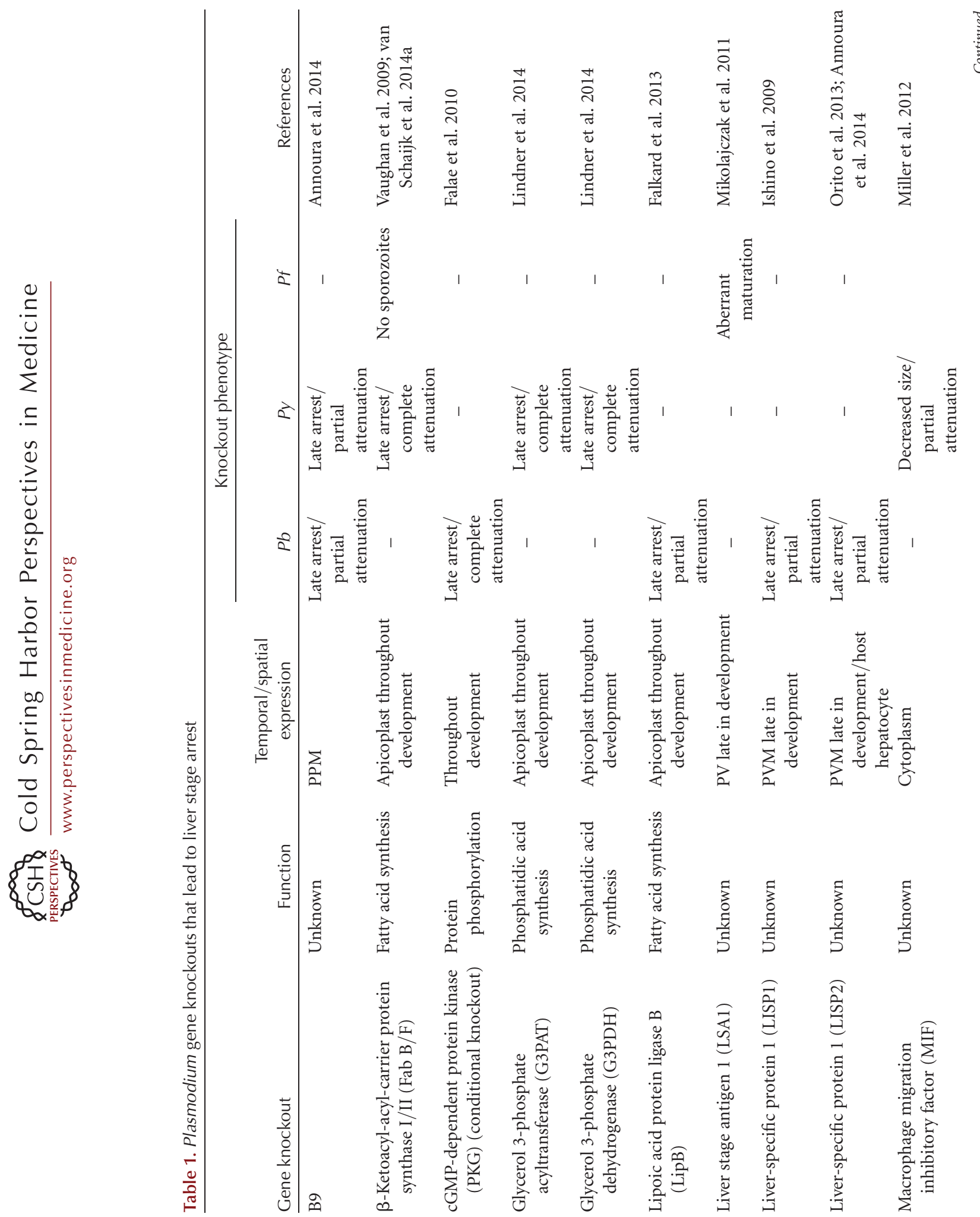


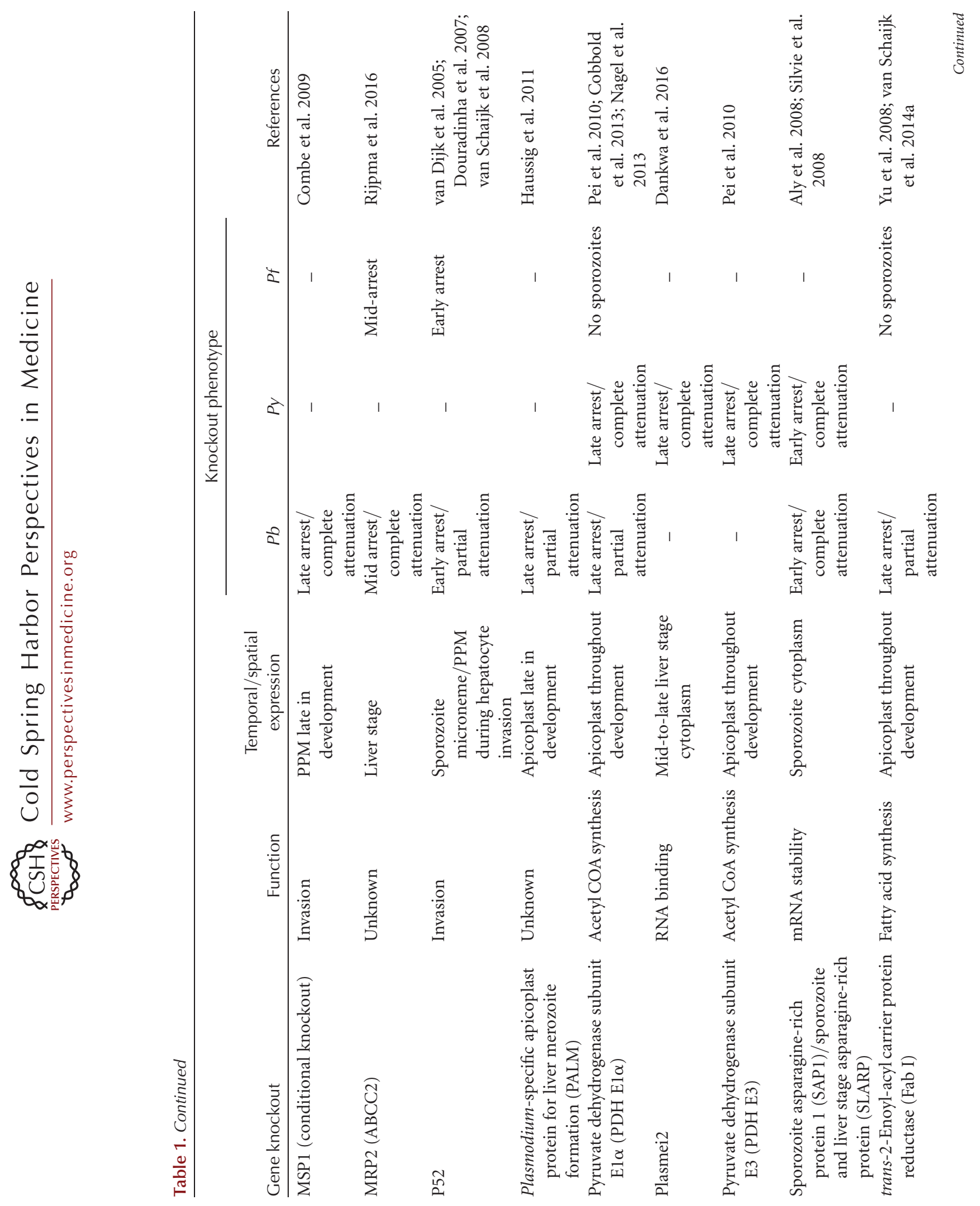


A.M. Vaughan and S.H.I. Kappe
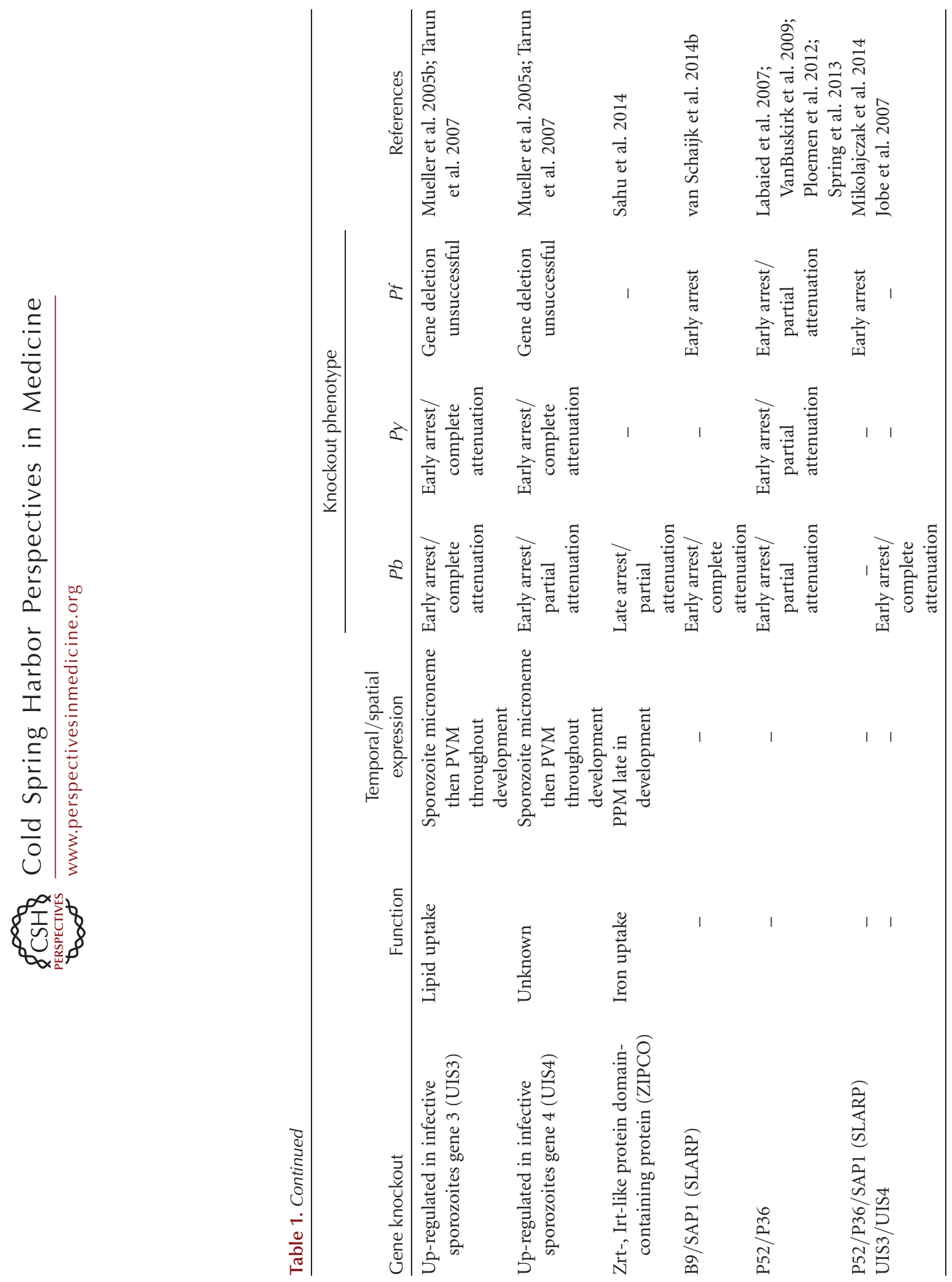
2040.org). However, P. falciparum malaria will not be eradicated globally without an effective preerythrocytic vaccine that will prevent the onset of disease-causing blood stage infection and onward transmission through the mosquito vector. In addition, the elusive $P$. vivax preerythrocytic hypnozoite forms must be targeted by radical cure drugs to ensure full malaria eradication, and thus drug development ought to place more emphasis on finding compounds with activity against liver stages. A robust understanding of hypnozoite biology might well be a prerequisite to develop new drugs that afford radical cure. A further critical research question in this context is whether preerythrocytic vaccination can be used to provide an "immunological radical cure" and as such should be a major aspect of $P$. vivax vaccine research. Overall, we must be continuously guided by the principle that novel and innovative intervention strategies will emerge only from critical research of parasite biology and the immunology of infection and vaccination.

\section{CONCLUDING REMARKS}

The past decade has seen an unprecedented progress in research on liver stage malaria. This has brought forth the identification of numerous parasite and host factors that are of critical importance to hepatocyte infection and intra-hepatocytic parasite development. Without doubt, research in the coming years will identify additional important factors. However, the study of parasite-hepatocyte interaction must now enter the next phase, by not only identifying critical host-pathogen interactions but also assembling these interactions into a temporal and spatial cascading network that fully delineates parasite infection of and development within hepatocytes at the molecular level, from the point of invasion to the release of merozoites. These studies will be likely performed with rodent malaria models, but the increased maturity of in vitro and in vivo hepatocyte infection models of human malaria parasites gives hope that at least some of this work can be achieved with medically relevant parasite species. This is particularly important for the study of $P$. vivax hypnozoites in gaining insights into the molecular mechanisms of their latency, their activation, and their interaction with hepatocytes during long periods of persistence.

Finally, identification of parasite molecules that are critical for liver stage development has transcended basic biology in that it enabled the development and use of genetically engineered, attenuated parasite strains for vaccination. It is hoped that the continued biological interrogation of liver stage malaria will carry on to bear fruit for parasite immunology and vaccine development, thereby potentiating its role in helping to develop new tools for the eradication of human malaria infection.

\section{ACKNOWLEDGMENTS}

Research being performed in the Kappe Laboratory is partly funded by the U.S. National Institutes of Health and the Bill and Melinda Gates Foundation. We thank laboratory members past and present for their scientific contributions as well as our dedicated insectary and vivarium staff.

\section{REFERENCES}

Albuquerque SS, Carret C, Grosso AR, Tarun AS, Peng X, Kappe SH, Prudencio M, Mota MM. 2009. Host cell transcriptional profiling during malaria liver stage infection reveals a coordinated and sequential set of biological events. BMC Genomics 10: 270.

Aly AS, Mikolajczak SA, Rivera HS, Camargo N, JacobsLorena V, Labaied M, Coppens I, Kappe SH. 2008. Targeted deletion of SAP1 abolishes the expression of infectivity factors necessary for successful malaria parasite liver infection. Mol Microbiol 69: 152-163.

Annoura T, van Schaijk BC, Ploemen IH, Sajid M, Lin JW, Vos MW, Dinmohamed AG, Inaoka DK, Rijpma SR, van Gemert GJ, et al. 2014. Two Plasmodium 6-Cys familyrelated proteins have distinct and critical roles in liverstage development. FASEB J 28: 2158-2170.

Azuma H, Paulk N, Ranade A, Dorrell C, Al-Dhalimy M, Ellis E, Strom S, Kay MA, Finegold M, Grompe M. 2007 Robust expansion of human hepatocytes in $\mathrm{Fah}^{-/-}$ Rag2 $2^{-/-} / \mathrm{Il} 2 \mathrm{rg}^{-/-}$mice. Nat Biotechnol 25: 903-910.

Baer K, Klotz C, Kappe SH, Schnieder T, Frevert U. 2007. Release of hepatic Plasmodium yoelii merozoites into the pulmonary microvasculature. PLoS Pathog 3: e171.

Baker RP, Wijetilaka R, Urban S. 2006. Two Plasmodium rhomboid proteases preferentially cleave different adhesins implicated in all invasive stages of malaria. PLoS Pathog 2: e113. 
A.M. Vaughan and S.H.I. Kappe

Bano N, Romano JD, Jayabalasingham B, Coppens I. 2007. Cellular interactions of Plasmodium liver stage with its host mammalian cell. Int J Parasitol 37: 1329-1341.

Behet MC, Foquet L, van Gemert GJ, Bijker EM, Meuleman P, Leroux-Roels G, Hermsen CC, Scholzen A, Sauerwein RW. 2014. Sporozoite immunization of human volunteers under chemoprophylaxis induces functional antibodies against pre-erythrocytic stages of Plasmodium falciparum. Malar J 13: 136.

Boonhok R, Rachaphaew N, Duangmanee A, Chobson P, Pattaradilokrat S, Utaisincharoen P, Sattabongkot J, Ponpuak M. 2016. LAP-like process as an immune mechanism downstream of IFN- $\gamma$ in control of the human malaria Plasmodium vivax liver stage. Proc Natl Acad Sci 113: E3519-E3528.

Burda PC, Roelli MA, Schaffner M, Khan SM, Janse CJ, Heussler VT. 2015. A Plasmodium phospholipase is involved in disruption of the liver stage parasitophorous vacuole membrane. PLoS Pathog 11: e1004760.

Butler NS, Schmidt NW, Vaughan AM, Aly AS, Kappe SH, Harty JT. 2011. Superior antimalarial immunity after vaccination with late liver stage-arresting genetically attenuated parasites. Cell Host Microbe 9: 451-462.

Clyde DF, Most H, McCarthy VC, Vanderberg JP. 1973. Immunization of man against sporozite-induced falciparum malaria. Am J Med Sci 266: 169-177.

Cobbold SA, Vaughan AM, Lewis IA, Painter HJ, Camargo N, Perlman DH, Fishbaugher M, Healer J, Cowman AF Kappe SH, et al. 2013. Kinetic flux profiling elucidates two independent acetyl-CoA biosynthetic pathways in Plasmodium falciparum. J Biol Chem 288: 36338-36350.

Combe A, Giovannini D, Carvalho TG, Spath S, Boisson B, Loussert C, Thiberge S, Lacroix C, Gueirard P, Menard R. 2009. Clonal conditional mutagenesis in malaria parasites. Cell Host Microbe 5: 386-396.

Coppi A, Natarajan R, Pradel G, Bennett BL, James ER, Roggero MA, Corradin G, Persson C, Tewari R, Sinnis P. 2011. The malaria circumsporozoite protein has two functional domains, each with distinct roles as sporozoites journey from mosquito to mammalian host. J Exp Med 208: 341-356.

Coppi A, Pinzon-Ortiz C, Hutter C, Sinnis P. 2005. The Plasmodium circumsporozoite protein is proteolytically processed during cell invasion. J Exp Med 201: 27-33.

Coppi A, Tewari R, Bishop JR, Bennett BL, Lawrence R, Esko JD, Billker O, Sinnis P. 2007. Heparan sulfate proteoglycans provide a signal to Plasmodium sporozoites to stop migrating and productively invade host cells. Cell Host Microbe 2: 316-327.

Cowman AF, Berry D, Baum J. 2012. The cellular and molecular basis for malaria parasite invasion of the human red blood cell. J Cell Biol 198: 961-971.

Dankwa DA, Davis MJ, Kappe SH, Vaughan AM. 2016. A Plasmodium yoelii Mei2-like RNA binding protein is essential for completion of liver stage schizogony. Infect Immun 84: 1336-1345.

Deretic V, Saitoh T, Akira S. 2013. Autophagy in infection, inflammation and immunity. Nat Rev Immunol 13: 722 737.

Doll KL, Harty JT. 2014. Correlates of protective immunity following whole sporozoite vaccination against malaria. Immunol Res 59: 166-176.
Douradinha B, van Dijk MR, Ataide R, van Gemert GJ, Thompson J, Franetich JF, Mazier D, Luty AJ, Sauerwein R, Janse CJ, et al. 2007. Genetically attenuated P36p-deficient Plasmodium berghei sporozoites confer long-lasting and partial cross-species protection. Int J Parasitol 37: 1511-1519.

Eickel N, Kaiser G, Prado M, Burda PC, Roelli M, Stanway RR, Heussler VT. 2013. Features of autophagic cell death in Plasmodium liver-stage parasites. Autophagy 9: 568580.

Ejigiri I, Sinnis P. 2009. Plasmodium sporozoite-host interactions from the dermis to the hepatocyte. Curr Opin Microbiol 12: 401-407.

Ejigiri I, Ragheb DR, Pino P, Coppi A, Bennett BL, SoldatiFavre D, Sinnis P. 2012. Shedding of TRAP by a rhomboid protease from the malaria sporozoite surface is essential for gliding motility and sporozoite infectivity. PLoS Pathog 8: e1002725.

Falae A, Combe A, Anburaj A, Carvalho TG, Menard R, Bhanot P. 2010. The role of Plasmodium berghei cGMP dependent protein kinase in late liver stage development. J Biol Chem 285: 3282-3288.

Falkard B, Kumar TR, Hecht LS, Matthews KA, Henrich PP, Gulati S, Lewis RE, Manary MJ, Winzeler EA, Sinnis P, et al. 2013. A key role for lipoic acid synthesis during Plasmodium liver stage development. Cell Microbiol 15: 1585-1604.

Ferreira A, Schofield L, Enea V, Schellekens H, van der Meide P, Collins WE, Nussenzweig RS, Nussenzweig V. 1986. Inhibition of development of exoerythrocytic forms of malaria parasites by $\gamma$-interferon. Science 232: 881-884.

Foquet L, Hermsen CC, van Gemert GJ, Van Braeckel E, Weening KE, Sauerwein R, Meuleman P, Leroux-Roels G. 2014. Vaccine-induced monoclonal antibodies targeting circumsporozoite protein prevent Plasmodium falciparum infection. J Clin Invest 124: 140-144.

Foquet L, Hermsen CC, Verhoye L, van Gemert GJ, Cortese R, Nicosia A, Sauerwein RW, Leroux-Roels G, Meuleman P. 2015. Anti-CD81 but not anti-SR-BI blocks Plasmodium falciparum liver infection in a humanized mouse model. J Antimicrob Chemother 70: 1784-1787.

Fowler RE, Margos G, Mitchell GH. 2004. The cytoskeleton and motility in apicomplexan invasion. Adv Parasitol 56: 213-263.

Frevert U, Sinnis P, Cerami C, Shreffler W, Takacs B, Nussenzweig V. 1993. Malaria circumsporozoite protein binds to heparan sulfate proteoglycans associated with the surface membrane of hepatocytes. J Exp Med 177: 1287-1298.

Gonzalez V, Combe A, David V, Malmquist NA, Delorme V, Leroy C, Blazquez S, Menard R, Tardieux I. 2009. Host cell entry by apicomplexa parasites requires actin polymerization in the host cell. Cell Host Microbe 5: 259-272.

Graewe S, Rankin KE, Lehmann C, Deschermeier C, Hecht L, Froehlke U, Stanway RR, Heussler V. 2011. Hostile takeover by Plasmodium: Reorganization of parasite and host cell membranes during liver stage egress. PLoS Pathog 7: e1002224.

Grutzke J, Rindte K, Goosmann C, Silvie O, Rauch C, Heuer D, Lehmann MJ, Mueller AK, Brinkmann V, Matuschewski $\mathrm{K}$, et al. 2014. The spatiotemporal dynamics and 
membranous features of the Plasmodium liver stage tubovesicular network. Traffic 15: 362-382.

Hanson KK, Mair GR. 2014. Stress granules and Plasmodium liver stage infection. Biol Open 3: 103-107.

Haussig JM, Matuschewski K, Kooij TW. 2011. Inactivation of a Plasmodium apicoplast protein attenuates formation of liver merozoites. Mol Microbiol 81: 1511-1525.

Inacio P, Zuzarte-Luis V, Ruivo MTG, Falkard B, Nagaraj N, Rooijers K, Mann M, Mair G, Fidock D, Mota MM. 2015. A role for ER stress during Plasmodium liver stage infection. EMBO Rep 16: 955-964.

Ishino T, Chinzei Y, Yuda M. 2005. Two proteins with 6-cys motifs are required for malarial parasites to commit to infection of the hepatocyte. Mol Microbiol 58: $1264-$ 1275.

Ishino T, Boisson B, Orito Y, Lacroix C, Bischoff E, Loussert C, Janse C, Menard R, Yuda M, Baldacci P. 2009. LISP1 is important for the egress of Plasmodium berghei parasites from liver cells. Cell Microbiol 11: 1329-1339.

Itoe MA, Sampaio JL, Cabal GG, Real E, Zuzarte-Luis V, March S, Bhatia SN, Frischknecht F, Thiele C, Shevchenko A, et al. 2014. Host cell phosphatidylcholine is a key mediator of malaria parasite survival during liver stage infection. Cell Host Microbe 16: 778-786.

Jayabalasingham B, Bano N, Coppens I. 2010. Metamorphosis of the malaria parasite in the liver is associated with organelle clearance. Cell Res 20: 1043-1059.

Jayabalasingham B, Voss C, Ehrenman K, Romano JD, Smith ME, Fidock DA, Bosch J, Coppens I. 2014. Characterization of the ATG8-conjugation system in 2 Plasmodium species with special focus on the liver stage: Possible linkage between the apicoplastic and autophagic systems? Autophagy 10: 269-284.

Jobe O, Lumsden J, Mueller AK, Williams J, Silva-Rivera H, Kappe SH, Schwenk RJ, Matuschewski K, Krzych U. 2007. Genetically attenuated Plasmodium berghei liver stages induce sterile protracted protection that is mediated by major histocompatibility complex class I-dependent interferon- $\gamma$-producing $\mathrm{CD}^{+}$T cells. J Infect Dis 196: 599-607.

Kaiser K, Camargo N, Kappe SH. 2003. Transformation of sporozoites into early exoerythrocytic malaria parasites does not require host cells. J Exp Med 197: 1045-1050.

Kappe S, Bruderer T, Gantt S, Fujioka H, Nussenzweig V Menard R. 1999. Conservation of a gliding motility and cell invasion machinery in Apicomplexan parasites. J Cell Biol 147: 937-944.

Kaushansky A, Metzger PG, Douglass AN, Mikolajczak SA, Lakshmanan V, Kain HS, Kappe SH. 2013a. Malaria parasite liver stages render host hepatocytes susceptible to mitochondria-initiated apoptosis. Cell Death Dis 4: e762.

Kaushansky A, Ye AS, Austin LS, Mikolajczak SA, Vaughan AM, Camargo N, Metzger PG, Douglass AN, Macbeath G, Kappe SH. 2013b. Suppression of host p53 is critical for Plasmodium liver-stage infection. Cell Rep 3: 630637.

Kaushansky A, Douglass AN, Arang N, Vigdorovich V, Dambrauskas N, Kain HS, Austin LS, Sather DN, Kappe SH. 2015. Malaria parasites target the hepatocyte receptor EphA2 for successful host infection. Science 350: 1089-1092.
Krotoski WA, Collins WE, Bray RS, Garnham PC, Cogswell FB, Gwadz RW, Killick-Kendrick R, Wolf R, Sinden R, Koontz LC, et al. 1982. Demonstration of hypnozoites in sporozoite-transmitted Plasmodium vivax infection. Am J Trop Med Hyg 31: 1291-1293.

Labaied M, Harupa A, Dumpit RF, Coppens I, Mikolajczak SA, Kappe SH. 2007. Plasmodium yoelii sporozoites with simultaneous deletion of P52 and P36 are completely attenuated and confer sterile immunity against infection. Infect Immun 75: 3758-3768.

Labaied M, Jayabalasingham B, Bano N, Cha SJ, Sandoval J, Guan G, Coppens I. 2011. Plasmodium salvages cholesterol internalized by LDL and synthesized de novo in the liver. Cell Microbiol 13: 569-586.

Liehl P, Mota MM. 2012. Innate recognition of malarial parasites by mammalian hosts. Int J Parasitol 42: 557566.

Liehl P, Zuzarte-Luis V, Chan J, Zillinger T, Baptista F, Carapau D, Konert M, Hanson KK, Carret C, Lassnig C, et al. 2014. Host-cell sensors for Plasmodium activate innate immunity against liver-stage infection. Nat Med 20: 4753.

Lindner SE, Sartain MJ, Hayes K, Harupa A, Moritz RL, Kappe SH, Vaughan AM. 2014. Enzymes involved in plastid-targeted phosphatidic acid synthesis are essential for Plasmodium yoelii liver-stage development. Mol Microbiol 91: 679-693.

Lopes da Silva M, Thieleke-Matos C, Cabrita-Santos L, Ramalho JS, Wavre-Shapton ST, Futter CE, Barral DC, Seabra MC. 2012. The host endocytic pathway is essential for Plasmodium berghei late liver stage development. Traffic 13: 1351-1363.

March S, Ng S, Velmurugan S, Galstian A, Shan J, Logan DJ, Carpenter AE, Thomas D, Sim BK, Mota MM, et al. 2013. A microscale human liver platform that supports the hepatic stages of Plasmodium falciparum and vivax. Cell Host Microbe 14: 104-115.

Mazier D, Landau I, Druilhe P, Miltgen F, Guguen-Guillouzo C, Baccam D, Baxter J, Chigot JP, Gentilini M. 1984. Cultivation of the liver forms of Plasmodium vivax in human hepatocytes. Nature 307: 367-369.

Mazier D, Beaudoin RL, Mellouk S, Druilhe P, Texier B, Trosper J, Miltgen F, Landau I, Paul C, Brandicourt O, et al. 1985. Complete development of hepatic stages of Plasmodium falciparum in vitro. Science 227: 440-442.

Meis JF, Verhave JP, Jap PH, Sinden RE, Meuwissen JH. 1983. Malaria parasites-Discovery of the early liver form. $\mathrm{Na}$ ture 302: 424-426.

Mikolajczak SA, Jacobs-Lorena V, MacKellar DC, Camargo N, Kappe SH. 2007. L-FABP is a critical host factor for successful malaria liver stage development. Int J Parasitol 37: 483-489.

Mikolajczak SA, Sacci JB Jr, De La Vega P, Camargo N, VanBuskirk K, Krzych U, Cao J, Jacobs-Lorena M, Cowman AF, Kappe SH. 2011. Disruption of the Plasmodium falciparum liver-stage antigen-1 locus causes a differentiation defect in late liver-stage parasites. Cell Microbiol 13: $1250-1260$.

Mikolajczak SA, Lakshmanan V, Fishbaugher M, Camargo N, Harupa A, Kaushansky A, Douglass AN, Baldwin M, Healer J, O’Neill M, et al. 2014. A next-generation genet- 
A.M. Vaughan and S.H.I. Kappe

ically attenuated Plasmodium falciparum parasite created by triple gene deletion. Mol Ther 22: 1707-1715.

Mikolajczak SA, Vaughan AM, Kangwanrangsan N, Roobsoong W, Fishbaugher M, Yimamnuaychok N, Rezakhani N, Lakshmanan V, Singh N, Kaushansky A, et al. 2015. Plasmodium vivax liver stage development and hypnozoite persistence in human liver-chimeric mice. Cell Host Microbe 17: 526-535.

Miller JL, Harupa A, Kappe SH, Mikolajczak SA. 2012. Plasmodium yoelii macrophage migration inhibitory factor is necessary for efficient liver-stage development. Infect Immun 80: 1399-1407.

Miller JL, Sack BK, Baldwin M, Vaughan AM, Kappe SH. 2014. Interferon-mediated innate immune responses against malaria parasite liver stages. Cell Rep 7: 436-447.

Molina-Cruz A, Garver LS, Alabaster A, Bangiolo L, Haile A, Winikor J, Ortega C, van Schaijk BC, Sauerwein RW, Taylor-Salmon E, et al. 2013. The human malaria parasite Pfs47 gene mediates evasion of the mosquito immune system. Science 340: 984-987.

Mueller AK, Camargo N, Kaiser K, Andorfer C, Frevert U, Matuschewski K, Kappe SH. 2005a. Plasmodium liver stage developmental arrest by depletion of a protein at the parasite-host interface. Proc Natl Acad Sci 102: 30223027.

Mueller AK, Labaied M, Kappe SH, Matuschewski K. 2005b. Genetically modified Plasmodium parasites as a protective experimental malaria vaccine. Nature 433: 164-167.

Nagel A, Prado M, Heitmann A, Tartz S, Jacobs T, Deschermeier C, Helm S, Stanway R, Heussler V. 2013. A new approach to generate a safe double-attenuated Plasmodium liver stage vaccine. Int J Parasitol 43: 503-514.

Ng S, Schwartz RE, March S, Galstian A, Gural N, Shan J, Prabhu M, Mota MM, Bhatia SN. 2015. Human iPSCderived hepatocyte-like cells support Plasmodium liverstage infection in vitro. Stem Cell Rep 4: 348-359.

Nussenzweig RS, Vanderberg J, Most H, Orton C. 1967. Protective immunity produced by the injection of $\mathrm{x}$-irradiated sporozoites of Plasmodium berghei. Nature 216: $160-162$.

Orito Y, Ishino T, Iwanaga S, Kaneko I, Kato T, Menard R, Chinzei Y, Yuda M. 2013. Liver-specific protein 2: A Plasmodium protein exported to the hepatocyte cytoplasm and required for merozoite formation. Mol Microbiol 87: 66-79.

Pei Y, Tarun AS, Vaughan AM, Herman RW, Soliman JM, Erickson-Wayman A, Kappe SH. 2010. Plasmodium pyruvate dehydrogenase activity is only essential for the parasite's progression from liver infection to blood infection. Mol Microbiol 75: 957-971.

Ploemen IH, Croes HJ, van Gemert GJ, Wijers-Rouw M, Hermsen CC, Sauerwein RW. 2012. Plasmodium berghei Deltap52\&p36 parasites develop independent of a parasitophorous vacuole membrane in Huh-7 liver cells. PLoS ONE 7: e50772.

Pradel G. 2007. Proteins of the malaria parasite sexual stages: Expression, function and potential for transmission blocking strategies. Parasitology 134: 1911-1929.

Prado M, Eickel N, De Niz M, Heitmann A, Agop-Nersesian C, Wacker R, Schmuckli-Maurer J, Caldelari R, Janse CJ, Khan SM, et al. 2015. Long-term live imaging reveals cytosolic immune responses of host hepatocytes against
Plasmodium infection and parasite escape mechanisms. Autophagy 11: 1561-1579.

Rieckmann KH, Carson PE, Beaudoin RL, Cassells JS, Sell KW. 1974. Letter: Sporozoite induced immunity in man against an Ethiopian strain of Plasmodium falciparum. Trans R Soc Trop Med Hyg 68: 258-259.

Rijpma SR, van der Velden M, Gonzalez-Pons M, Annoura T, van Schaijk BC, van Gemert GJ, van den Heuvel JJ, Ramesar J, Chevalley-Maurel S, Ploemen IH, et al. 2016. Multidrug ATP-binding cassette transporters are essential for hepatic development of Plasmodium sporozoites. Cell Microbiol 18: 369-383.

Risco-Castillo V, Topcu S, Son O, Briquet S, Manzoni G, Silvie O. 2014. CD81 is required for rhoptry discharge during host cell invasion by Plasmodium yoelii sporozoites. Cell Microbiol 16: 1533-1548.

Sacci JB Jr, Alam U, Douglas D, Lewis J, Tyrrell DL, Azad AF, Kneteman NM. 2006. Plasmodium falciparum infection and exoerythrocytic development in mice with chimeric human livers. Int J Parasitol 36: 353-360.

Sack BK, Miller JL, Vaughan AM, Douglass A, Kaushansky A, Mikolajczak S, Coppi A, Gonzalez-Aseguinolaza G, Tsuji M, Zavala F, et al. 2014. Model for in vivo assessment of humoral protection against malaria sporozoite challenge by passive transfer of monoclonal antibodies and immune serum. Infect Immun 82: 808-817.

Sack BK, Keitany GJ, Vaughan AM, Miller JL, Wang R, Kappe SH. 2015. Mechanisms of stage-transcending protection following immunization of mice with late liver stage-arresting genetically attenuated malaria parasites. PLoS Pathog 11: e1004855.

Sahu T, Boisson B, Lacroix C, Bischoff E, Richier Q, Formaglio P, Thiberge S, Dobrescu I, Menard R, Baldacci P. 2014. ZIPCO, a putative metal ion transporter, is crucial for Plasmodium liver-stage development. EMBO Mol Med 6: 1387-1397.

Sala KA, Nishiura H, Upton LM, Zakutansky SE, Delves MJ, Iyori M, Mizutani M, Sinden RE, Yoshida S, Blagborough AM. 2015. The Plasmodium berghei sexual stage antigen PSOP12 induces anti-malarial transmission blocking immunity both in vivo and in vitro. Vaccine 33: 437-445.

Sattabongkot J, Yimamnuaychoke N, Leelaudomlipi S, Rasameesoraj M, Jenwithisuk R, Coleman RE, Udomsangpetch R, Cui L, Brewer TG. 2006. Establishment of a human hepatocyte line that supports in vitro development of the exoerythrocytic stages of the malaria parasites Plasmodium falciparum and P. vivax. Am J Trop Med Hyg 74: 708-715.

Seder RA, Chang LJ, Enama ME, Zephir KL, Sarwar UN, Gordon IJ, Holman LA, James ER, Billingsley PF, Gunasekera A, et al. 2013. Protection against malaria by intravenous immunization with a nonreplicating sporozoite vaccine. Science 341: 1359-1365.

Silvie O, Goetz K, Matuschewski K. 2008. A sporozoite asparagine-rich protein controls initiation of Plasmodium liver stage development. PLoS Pathog 4: e1000086.

Silvie O, Rubinstein E, Franetich JF, Prenant M, Belnoue E, Renia L, Hannoun L, Eling W, Levy S, Boucheix C, et al. 2003. Hepatocyte CD81 is required for Plasmodium falciparum and Plasmodium yoelii sporozoite infectivity. Nat Med 9: 93-96. 
Silvie O, Charrin S, Billard M, Franetich JF, Clark KL, van Gemert GJ, Sauerwein RW, Dautry F, Boucheix C, Mazier $\mathrm{D}$, et al. 2006. Cholesterol contributes to the organization of tetraspanin-enriched microdomains and to CD81-dependent infection by malaria sporozoites. J Cell Sci 119: 1992-2002.

Spring M, Murphy J, Nielsen R, Dowler M, Bennett JW, Zarling S, Williams J, de la Vega P, Ware L, Komisar J, et al. 2013. First-in-human evaluation of genetically attenuated Plasmodium falciparum sporozoites administered by bite of Anopheles mosquitoes to adult volunteers. Vaccine 31: 4975-4983.

Stanway RR, Witt T, Zobiak B, Aepfelbacher M, Heussler VT. 2009. GFP-targeting allows visualization of the apicoplast throughout the life cycle of live malaria parasites. Biol Cell 101: $415-430$

Stanway RR, Mueller N, Zobiak B, Graewe S, Froehlke U, Zessin PJ, Aepfelbacher M, Heussler VT. 2011. Organelle segregation into Plasmodium liver stage merozoites. Cell Microbiol 13: 1768-1782.

Sturm A, Amino R, van de Sand C, Regen T, Retzlaff S, Rennenberg A, Krueger A, Pollok JM, Menard R, Heussler VT. 2006. Manipulation of host hepatocytes by the malaria parasite for delivery into liver sinusoids. Science 313: $1287-1290$.

Sturm A, Graewe S, Franke-Fayard B, Retzlaff S, Bolte S, Roppenser B, Aepfelbacher M, Janse C, Heussler V. 2009. Alteration of the parasite plasma membrane and the parasitophorous vacuole membrane during exoerythrocytic development of malaria parasites. Protist 160: 51-63.

Tardif KD, Siddiqui A. 2003. Cell surface expression of major histocompatibility complex class I molecules is reduced in hepatitis $C$ virus subgenomic replicon-expressing cells. J Virol 77: 11644-11650.

Tarun AS, Baer K, Dumpit RF, Gray S, Lejarcegui N, Frevert U, Kappe SH. 2006. Quantitative isolation and in vivo imaging of malaria parasite liver stages. Int J Parasitol 36: $1283-1293$.

Tarun AS, Dumpit RF, Camargo N, Labaied M, Liu P, Takagi A, Wang R, Kappe SH. 2007. Protracted sterile protection with Plasmodium yoelii pre-erythrocytic genetically attenuated parasite malaria vaccines is independent of significant liver-stage persistence and is mediated by $\mathrm{CD} 8^{+}$ T cells. J Infect Dis 196: 608-616.

Tarun AS, Peng X, Dumpit RF, Ogata Y, Silva-Rivera H, Camargo N, Daly TM, Bergman LW, Kappe SH. 2008. A combined transcriptome and proteome survey of malaria parasite liver stages. Proc Natl Acad Sci 105: 305310.

Templeton TJ, Kaslow DC. 1999. Identification of additional members define a Plasmodium falciparum gene superfamily which includes Pfs48/45 and Pfs230. Mol Biochem Parasitol 101: 223-227.

Thieleke-Matos C, da Silva ML, Cabrita-Santos L, Pires CF Ramalho JS, Ikonomov O, Seixas E, Shisheva A, Seabra MC, Barral DC. 2014. Host PI (3,5)P2 activity is required for Plasmodium berghei growth during liver stage infection. Traffic 15: 1066-1082.

VanBuskirk KM, O’Neill MT, De La Vega P, Maier AG, Krzych U, Williams J, Dowler MG, Sacci JB Jr, Kangwanrangsan N, Tsuboi T, et al. 2009. Pre-erythrocytic, live- attenuated Plasmodium falciparum vaccine candidates by design. Proc Natl Acad Sci 106: 13004-13009.

van de Sand C, Horstmann S, Schmidt A, Sturm A, Bolte S, Krueger A, Lutgehetmann M, Pollok JM, Libert C, Heussler VT. 2005. The liver stage of Plasmodium berghei inhibits host cell apoptosis. Mol Microbiol 58: 731-742.

van Dijk MR, Douradinha B, Franke-Fayard B, Heussler V, van Dooren MW, van Schaijk B, van Gemert GJ, Sauerwein RW, Mota MM, Waters AP, et al. 2005. Genetically attenuated, P36p-deficient malarial sporozoites induce protective immunity and apoptosis of infected liver cells Proc Natl Acad Sci 102: 12194-12199.

van Dijk MR, van Schaijk BC, Khan SM, van Dooren MW, Ramesar J, Kaczanowski S, van Gemert GJ, Kroeze H, Stunnenberg HG, Eling WM, et al. 2010. Three members of the 6-cys protein family of Plasmodium play a role in gamete fertility. PLoS Pathog 6: e1000853.

van Schaijk BC, Janse CJ, van Gemert GJ, van Dijk MR, Gego A, Franetich JF, van de Vegte-Bolmer M, Yalaoui S, Silvie O, Hoffman SL, et al. 2008. Gene disruption of Plasmodium falciparum 552 results in attenuation of malaria liver stage development in cultured primary human hepatocytes. PLoS ONE 3: e3549.

van Schaijk BC, Kumar TR, Vos MW, Richman A, van Gemert GJ, Li T, Eappen AG, Williamson KC, Morahan BJ, Fishbaugher M, et al. 2014a. Type II fatty acid biosynthesis is essential for Plasmodium falciparum sporozoite development in the midgut of Anopheles mosquitoes. Eukaryot Cell 13: 550-559.

van Schaijk BC, Ploemen IH, Annoura T, Vos MW, Foquet L, van Gemert GJ, Chevalley-Maurel S, van de VegteBolmer M, Sajid M, Franetich JF, et al. 2014b. A genetically attenuated malaria vaccine candidate based on P. falciparum b9/slarp gene-deficient sporozoites. eLife 3: $\mathrm{e} 03582$.

Vaughan AM, O'Neill MT, Tarun AS, Camargo N, Phuong TM, Aly AS, Cowman AF, Kappe SH. 2009. Type II fatty acid synthesis is essential only for malaria parasite late liver stage development. Cell Microbiol 11: 506-520.

Vaughan AM, Mikolajczak SA, Wilson EM, Grompe M, Kaushansky A, Camargo N, Bial J, Ploss A, Kappe SH. 2012. Complete Plasmodium falciparum liver-stage development in liver-chimeric mice. J Clin Invest 122: 3618-3628.

Vaughan AM, Pinapati RS, Cheeseman IH, Camargo N, Fishbaugher M, Checkley LA, Nair S, Hutyra CA, Nosten FH, Anderson TJ, et al. 2015. Plasmodium falciparum genetic crosses in a humanized mouse model. Nat Methods 12: 631-633.

Vinetz JM. 2005. Plasmodium ookinete invasion of the mosquito midgut. Curr Top Microbiol Immunol 295: $357-$ 382.

Yalaoui S, Huby T, Franetich JF, Gego A, Rametti A, Moreau M, Collet X, Siau A, van Gemert GJ, Sauerwein RW, et al. 2008. Scavenger receptor BI boosts hepatocyte permissiveness to Plasmodium infection. Cell Host Microbe 4: 283-292.

Yu M, Kumar TR, Nkrumah LJ, Coppi A, Retzlaff S, Li CD, Kelly BJ, Moura PA, Lakshmanan V, Freundlich JS, et al. 2008. The fatty acid biosynthesis enzyme FabI plays a key role in the development of liver-stage malarial parasites. Cell Host Microbe 4: 567-578. 


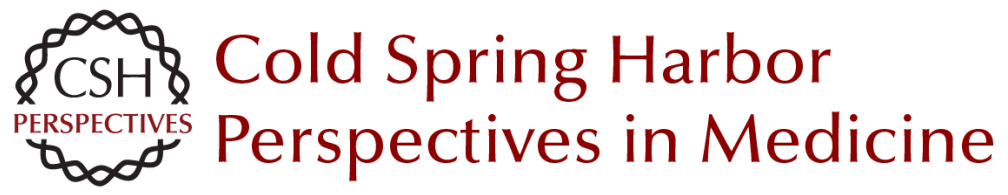

\section{Malaria Parasite Liver Infection and Exoerythrocytic Biology}

Ashley M. Vaughan and Stefan H.I. Kappe

Cold Spring Harb Perspect Med 2017; doi: 10.1101/cshperspect.a025486 originally published online February 27, 2017

\section{Subject Collection Malaria: Biology in the Era of Eradication}

Modern Vector Control

Neil F. Lobo, Nicole L. Achee, John Greico, et al.

Anopheline Reproductive Biology: Impacts on Vectorial Capacity and Potential Avenues for

Malaria Control Sara N. Mitchell and Flaminia Catteruccia

Current and Future Prospects for Preventing Malaria Transmission via the Use of Insecticides Hilary Ranson

Molecular Signaling Involved in Entry and Exit of Malaria Parasites from Host Erythrocytes Shailja Singh and Chetan E. Chitnis

Vaccines to Accelerate Malaria Elimination and Eventual Eradication Julie Healer, Alan F. Cowman, David C. Kaslow, et al.

Immune Responses in Malaria Carole A. Long and Fidel Zavala

Antimalarial Drug Resistance: A Threat to Malaria Elimination Didier Menard and Arjen Dondorp

Malaria during Pregnancy Michal Fried and Patrick E. Duffy
Malaria Pathogenesis Danny A. Milner, Jr.

Determinants of Malaria Transmission at the Population Level Teun Bousema and Chris Drakeley

\section{Host Cell Tropism and Adaptation of Blood-Stage} Malaria Parasites: Challenges for Malaria

Elimination Caeul Lim, Selasi Dankwa, Aditya S. Paul, et al.

Malaria Transmission and Prospects for Malaria Eradication: The Role of the Environment Marcia C. Castro

The Biology of Plasmodium vivax John H. Adams and Ivo Mueller

Malaria Genomics in the Era of Eradication Daniel E. Neafsey and Sarah K. Volkman

Malaria Epigenetics Alfred Cortés and Kirk W. Deitsch

Malaria Parasite Liver Infection and Exoerythrocytic Biology Ashley M. Vaughan and Stefan H.I. Kappe

For additional articles in this collection, see http://perspectivesinmedicine.cshlp.org/cgi/collection/ 